\title{
Colorectal cancer in the elderly: characteristics and short term results
}

\author{
Juan José Arenal Vera ${ }^{1}$, Claudia Tinoco Carrasco ${ }^{1}$, Araceli del Villar Negro ${ }^{2}$, \\ Fernando Labarga Rodríguez ${ }^{1}$, Alberto Delgado Mucientes ${ }^{1}$ and Miguel Ángel Cítores ${ }^{1}$
}

Departments of ${ }^{I}$ Surgery and ${ }^{2}$ Pathology. Hospital Universitario Río Hortega. Valladolid, Spain

\begin{abstract}
Objective: to analyse the characteristics of colorectal cancer in elderly patients and to assess the outcomes of treatment.

Materials and methods: the study included 1924 patients diagnosed with colorectal cancer during a 22 year period (19852007). We analysed patient clinical and demographic characteristics as well as their treatment and its outcome.

Results: there was an increase in emergency surgery with age, increasing from $13 \%$ among patients under 80 years of age to $47 \%$ in those over 90 years of age $(p=0.0001)$. On the other hand, the overall percentage of patients who underwent surgical treatment decreased from $96 \%$ in patients younger than 80 years of age, to $85 \%$ and $59 \%$ in octogenarians and nonagenarians, respectively ( $p$ $=0.0001$ ), and there was a similar pattern in the rates of curative surgery among patients who underwent surgery. The overall mortality of patients who underwent surgery was $8 \%$ (141 out of 1,769 ), increasing from $4 \%$ in patients younger than 70 years of age to $25 \%$ in those over 90 ( $p=0.0001)$. Multivariate analysis showed that the factors associated with mortality were the emergency nature of the surgery $(p=0.001)$, the ASA grade $(p=0.0001)$, and the presence of systemic complications $(p=0.0001)$, the weight of age decreasing significantly with respect to the univariate analysis ( $\mathrm{p}=$ 0.013).

Conclusions: there is an increase in the rate of complicated forms of colorectal cancer with increasing age of patients. In addition, there is a dramatic decrease in the rate of curative tumour resection with increasing age. Intraoperative mortality for colorectal cancer in octogenarians and nonagenarians is more closely related to the nature and intent of the surgery (elective or emergency; palliative or curative), the perioperative risk (ASA grade), and severe systemic complications, than to age.
\end{abstract}

Key words: Colorectal cancer. Octogenarians. Nonagenarians. Mortality.

Received: 09-02-11.

Accepted: 29-03-11

Correspondence: Juan José Arenal Vera. Department of Surgery. Hospital Universitario Río Hortega. C/ C/ Dulzaina, nº 2. 47012 Valladolid. e-mail: jujoarve@yahoo.com
Arenal Vera JJ, Tinoco Carrasco C, Del Villar Negro A, Labarga Rodríguez F, Delgado Mucientes A, Cítores MA. Colorectal cancer in the elderly: characteristics and short term results. Rev Esp Enferm Dig 2011; 103: 408-415.

\section{INTRODUCTION}

In 2000, colorectal cancer caused $11 \%$ and $15 \%$ of deaths due to cancer in men and women, respectively in Spain (1). Cancer is a common disease in octogenarians and nonagenarians and is currently a healthcare problem of great importance. In particular, colorectal cancer represents more than $50 \%$ of the new cases of cancer in nonagenarians. Nevertheless, there are few of publications focusing on this disease in octogenarians, and hardly any relating to patients older than 90 years of age (2-6). Indeed, there is little in literature concerning the impact of surgery in general on octogenarians and nonagenarians (7-12).

Specialists have to deal with certain challenges when it comes to deciding treatment for older patients with colorectal cancer. In particular, typically there is a great variability in ageing between individuals, so that there is no often correlation between chronological and biological age. Patients of the same age may have no associated disorders, with a good level of physical activity and a long life expectancy, or, on the other hand, have multiple associated disorders and be very weak due to severe functional impairments (heart, bronchopulmonary, renal and cerebrovascular disorders).

Surgical standards have improved in recent years, but we have to bear in mind comorbidities when taking decisions concerning weak patients. Although high rates of mortality and a decrease in the overall survival have been reported for elderly patients, compared to their younger counterparts, careful selection should help us identify patients who may benefit from major surgery. 
The aim of this study was to assess the treatment of colorectal cancer in octogenarian and nonagenarian patients and to improve our understanding of the short term outcomes of major surgery in these types of patients.

\section{MATERIAL AND METHODS}

The cohort was composed of 1924 patients diagnosed with colorectal cancer over a period of 22 years (19852007). The series was divided into four age groups: $<70$ (791 cases), 70-79 (627 cases), 80-89 (429 cases) and $\geq 90$ (74 cases) years of age. The variables analysed were: a) demographic characteristics; b) the nature and intent of the main operation, namely, whether it was an elective or an emergency procedure and the curative or palliative intention of the surgery; c) immediate operative outcomes, in terms of morbidity (local and systemic morbidity); and d) pathological characteristics: diagnosis, tumour differentiation, length and width of the tumour, infiltration of the intestinal wall and of other tissues, number of lymph nodes found and number invaded in resected tissue, vascular and perineural invasion, synchronous lesions, involvement of surgical margins, distance from the anus in rectal cancer cases, size of disease free margins (from tumour to the edge of the resected tissue), and presence of residual tumour after surgery. The cancer was staged using the TNM cancer staging system and the perioperative risk associated with anaesthesia was assessed using the ASA (American Society of Anesthesiologists) criteria.

\section{Statistical analysis}

For continuous variables, the Kolmogorov-Smirnov test was used to compare groups, means (and standard deviations) were calculated to analyse distributions, and differences between parametric variables were assessed using the paired and the unpaired Student's t-tests, while nonparametric variables were assessed using Friedman, Wilcoxon, K Kruskal and U-Mann tests. The differences between qualitative variables were analysed using the Chi square test with Yates correction and Fisher's exact test. A multiple regression analysis was performed to determine the weight of the variables found to be related to mortality in the univariate analysis. Age was not introduced as continuous variable, but rather at the defining characteristic for the four groups analysed. Similarly, the variables related to local and systemic complications were analysed as a dichotomous variables (yes/no). Only p values $<0.01$ were considered to be significant.

\section{RESULTS}

The characteristics of patients with colorectal cancer in our series are shown in table I. Slightly over half (58\%) of
Table I. Demographic characteristic of the patients with colorectal cancer

\begin{tabular}{lll}
\hline & Number & $\%$ \\
\hline Sex & & \\
Men & 1121 & 58 \\
Women & 803 & 42 \\
Age & & \\
$<70$ & 792 & 41 \\
$70-79$ & 629 & 33 \\
$80-89$ & 429 & 22 \\
$\geq 90$ & 74 & 4 \\
All ages & 1924 & 100 \\
\hline
\end{tabular}

the patients were men and the median of age of the series was 72 years (range 23-99). A total of $60 \%$ of the patients were 70 years old or older, while $26 \%$ of the patients were 80 or older.

Table II describes the distribution of the variables studied as a function of different age groups. We observed an increase in female patients with increasing age, women representing $61 \%$ of the group aged 90 or over $(p=0.0001)$. There was an increase in the rate of emergency surgery from the age of 80 onwards, ranging from $13 \%$ in those younger than 80 years old to $47 \%$ among those older than $90\left(\mathrm{p}=0.0001,3 \mathrm{df}, \mathrm{c}^{2}=63.98\right)$. That is, the rate of emergency surgery with respect to the younger patients doubled in those over the age of 80 , and trebled for those over the age of $90(\mathrm{p}=0.0001)$. There was also a progressive increase in patients with associated diseases as a function of age. A total of $66 \%$ of the patients younger than 70 years old did not have any associated diseases, compared to rates of associated diseases of $38 \%, 36 \%$ and $31 \%$ among those $70-79,80-89$ and 90 or more years of age, respectively ( $\mathrm{p}$ $=0.0001)$. In particular, cases of diabetes, high blood pressure, chronic bronchopulmonary disease, and heart disease significantly increased with age. A total of $72 \%$ of patients younger than 70 years of age were classed as ASA I-II compared to $54 \%, 43 \%$ and $33 \%$ in the groups aged $70-79,80-$ 89 and 90 and over, respectively $(\mathrm{p}=0.0001)$. In parallel with this fall, there was a progressive increase in the percentage of ASA IV and V patients. With increasing age, there were more of cases of cancer of the right colon and a progressive decrease in rectal cancer $(\mathrm{p}=0.0001)$, though there were no significant differences between the age groups with respect to the cancer of the left colon. From the age of eighty onwards the percentage of patients with stage I cancer fell, from $14 \%$ to $7 \%$ among those $80-89$ years old and further to $4 \%$ among those aged 90 or over. The percentage of patients not staged was just $3 \%$ for the group younger than 70 , rising to $6 \%$ for the 70 - to 79 -year-olds, $18 \%$ for 80 - to 89 -year-olds and $45 \%$ among those aged 90 years and over $(\mathrm{p}=0.0001)$

The mean time from the onset of symptoms to seeking medical attention was 3.95 months for the overall series, 
Table II. Comparative analysis of the series as a function of age group

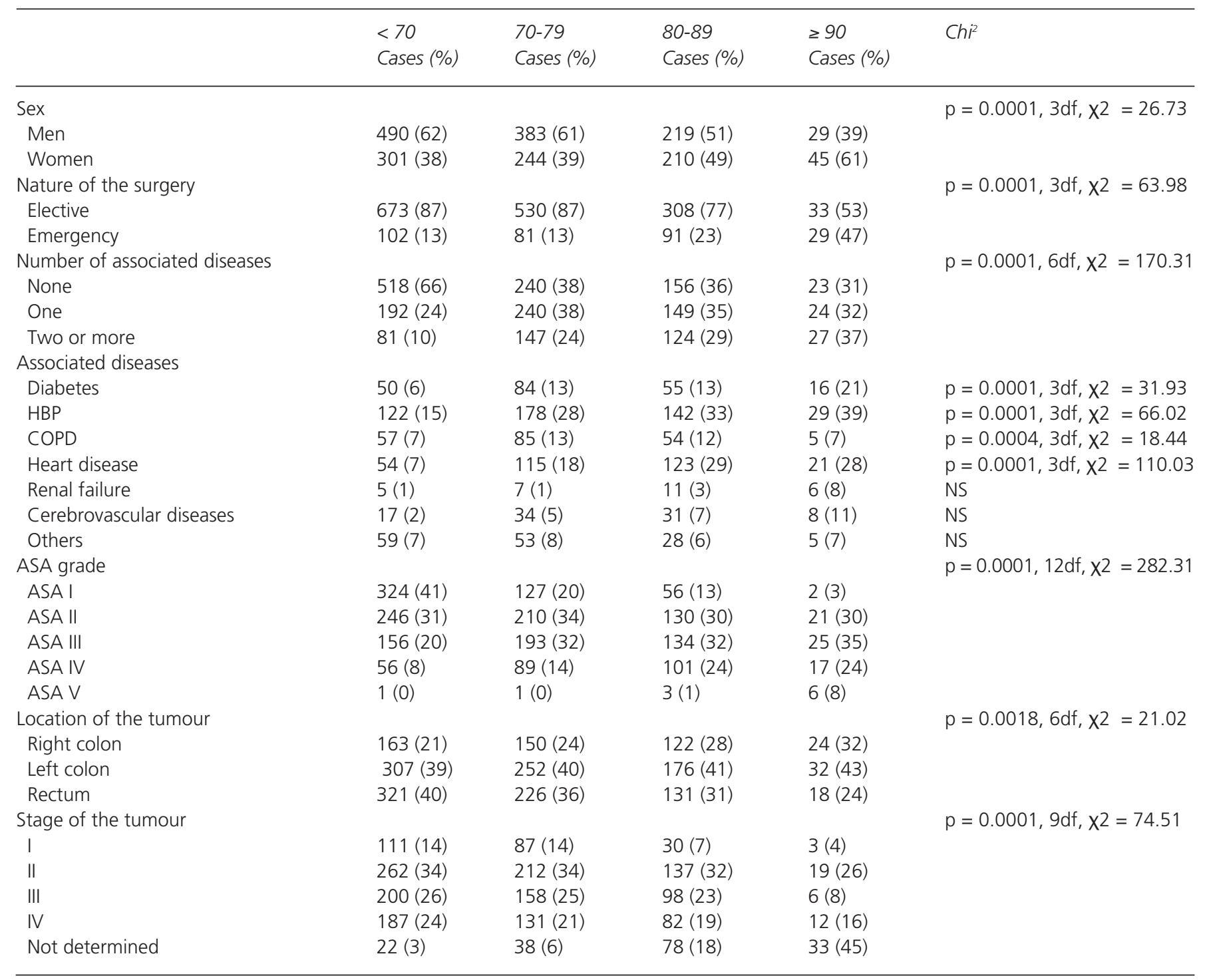

HBP: high blood pressure; COPD: chronic obstructive pulmonary disease.

being 4.10, 3.96, 3.78 and 3.02 months for the $\leq 70,70-79$, $80-89$ and $\geq 90$ year old groups respectively (NS).

Table III shows the comparative analysis of the main symptoms of colorectal cancer, distributed by age groups. The symptoms which became the most common with increasing age were pain, anaemia, and intestinal occlusion, while rectal bleeding and tenesmus decreased with age.

Table IV lists the rates of surgery by age group. Notably, both the total rate of surgery and that of resection dramatically decrease from the age of 80 onwards. Among those who underwent surgery, the rate of surgery with intention to cure was $80 \%, 79 \%, 74 \%$ and $66 \%$ for the $\leq 70,70-79$, $80-89$, and $\geq 90$ year old age groups $(\mathrm{p}=0.0095)$.

The mortality analysis for the series is shown in Table $\mathrm{V}$. Overall mortality of patients who underwent surgery was $8 \%$ (141 out of 1769), increasing from $4 \%$ in the $\leq 70$ age group to $25 \%$ in the $\geq 90$ year old age group. In the univariate analysis, as well as age, the nature of the surgery (elective or emergency, $\mathrm{p}=0.0001$ ), its intent (curative or palliative, $p=0.0001)$, the ASA grade $(p=0.0001)$ and the occurrence of systemic complications were found to be significantly associated with the increase of mortality.

Table VI indicates that there we found no significant differences in mortality among patients who were biologically strong (ASA I-II) as a function of age group.

Indeed, logistic regression analysis (Table VII) showed that the factors related to postoperative mortality were emergency surgery $(p=0.001)$, ASA grade $(p=0.0001)$ and the occurrence of systemic complications $(\mathrm{p}=0.0001)$.

Morbidity in patients who underwent surgery is reported by age group in Table VIII. A total of 35\% of these patients $\leq 70$ years of age had no postoperative complications, com- 
Table III. Symptomatology by age group

\begin{tabular}{|c|c|c|c|c|c|}
\hline & $\begin{array}{l}<70 \\
\text { Cases (\%) }\end{array}$ & $\begin{array}{l}70-79 \\
\text { Cases (\%) }\end{array}$ & $\begin{array}{l}80-89 \\
\text { Cases (\%) }\end{array}$ & $\begin{array}{l}\geq 90 \\
\text { Cases (\%) }\end{array}$ & $\mathrm{Chi}^{2}$ \\
\hline Rectal bleeding & $375(47)$ & $295(47)$ & $147(34)$ & $14(19)$ & $p=0.0001$ \\
\hline Change of intestinal habit & $229(29)$ & $186(30)$ & $109(25)$ & $17(23)$ & $p=0.32$ \\
\hline Anaemia & $150(19)$ & $173(28)$ & $148(35)$ & $31(42)$ & $p=0.0001$ \\
\hline Occlusion & $89(11)$ & $71(11)$ & $82(19)$ & $30(41)$ & $p=0.0001$ \\
\hline Sub-occlusion & $37(5)$ & $30(5)$ & $27(6)$ & $3(4)$ & $p=0.60$ \\
\hline Melaena & $39(5)$ & $37(7)$ & $26(6)$ & $2(3)$ & $p=0.56$ \\
\hline Asthenia & $122(15)$ & $163(26)$ & $104(24)$ & $11(15)$ & $p=0.0001$ \\
\hline Anorexia & $118(15)$ & $151(24)$ & $98(23)$ & $13(18)$ & $p=0.0003$ \\
\hline Weight loss & $160(20)$ & $175(28)$ & $107(25)$ & $14(19)$ & $p=0.0056$ \\
\hline
\end{tabular}

pared to $41 \%, 47 \%$ and $50 \%$ of those in the $70-79,80-89$ and $\geq 90$ year old age groups $(\mathrm{p}=0.001)$. Differences in rates between the four age groups were not significant with regards to local complications, but were significant for systemic complications, the rates being $13 \%, 19 \%, 28 \%$ and $30 \%$ for the $\leq 70,70-79,80-89$ and $\geq 90$ year old age groups, respectively $(\mathrm{p}=0.0001)$. This increase of systemic complications was found to be due to increases in cardiac, respiratory and renal complications with age.

The average postoperative stays in hospital for patients who underwent surgery were 16.3 (SD 10.4), 17.2 (SD 12.2), 16.6 (SD 9.6), and 15.4 (SD 10.3) days for the $\leq 70,70-79$, $80-89$ and $\geq 90$ year old age groups, respectively (NS).

\section{DISCUSSION}

In our series, 59\% of the patients were over 70 years old, and $26 \%$ were 80 years old or more. These figures are consistent with data from other series of colorectal cancer patients, in which the percentage of patients over 75 years of age ranges between $22 \%$ and $45 \%(5,14)$. The increase of female patients as a function of age is also found in other series and is explained by the higher life expectancy of women (15). As has been described previously $(5,16-20)$, more than $60 \%$ of patients aged 80 or older had associated comorbidities. Similarly, there was an increase in perioperative risk (ASA grade) with age.

The greater prevalence of complicated forms of the disease is consistent with the increase in emergency surgery observed in older patients, from $13 \%$ in those younger than 80 years old to $23 \%$ in those $80-89$ years old and $47 \%$ in patients over the age of 90 . In other series, complicated forms of the disease reached figures similar to our data, in patients aged 80 or above $(5,6,14,18,20)$.

The increase in cancers of the right colon and the decrease in the prevalence of rectal cancer in elderly patients are well known $(15,20,21)$. This difference in tumour location explains the lower prevalence of rectal haemorrhage and tenesmus with increasing age, evident in our study. On the other hand, anaemia and intestinal occlusion increase progressively with age, being found in more than $40 \%$ of the nonagenarian patients in our series.

Despite the fact that most cases of colorectal cancer are found in the elderly, it has been suggested that they are undertreated, both in early and advanced stages of the disease (3-5). General practitioners, surgeons, gastroenterologists and oncologists tend to assess patients according to their chronological age rather than their biological age. This may explain the finding in our series that a large number

Table IV. Surgical treatment by age groups

\begin{tabular}{llllll}
\hline & $\begin{array}{l}<0 \\
\text { Cases (\%) }\end{array}$ & $\begin{array}{l}70-79 \\
\text { Cases (\%) }\end{array}$ & $\begin{array}{l}80-89 \\
\text { Cases (\%) }\end{array}$ & $\begin{array}{l}\geq 90 \\
\text { Cases (\%) }\end{array}$ & Chi \\
\hline Rate of patients who underwent surgery & $762(96)$ & $599(95)$ & $364(85)$ & $44(59)$ & $P=0.0001,3 \mathrm{df}, \chi^{2}=166.97$ \\
Rate of resections in patients who underwent surgery & $709(93)$ & $539(88)$ & $292(80)$ & $32(72)$ & $P=0.0001,3 \mathrm{df}, \chi^{2}=50.16$ \\
Overall rate of resections & $709(90)$ & $539(84)$ & $292(68)$ & $32(43)$ & $P=0.0001,3 \mathrm{df}, \chi^{2}=50.16$ \\
Rate of curative-intent surgery & $615(80)$ & $468(78)$ & $267(74)$ & $29(66)$ & $P=0.0095,3 \mathrm{df}, \chi^{2}=1.46$ \\
\hline
\end{tabular}


Table V. Mortality analysis

\begin{tabular}{|c|c|c|c|c|}
\hline & Cases & Exitus & $\%$ & \\
\hline Sex & & & & NS \\
\hline Men & 1037 & 85 & 8 & \\
\hline Women & 732 & 56 & 8 & \\
\hline Age & & & & $p=0.0001,3 d f, \chi^{2}=50.29$ \\
\hline$<70$ & 762 & 32 & 4 & \\
\hline $70-79$ & 600 & 47 & 8 & \\
\hline $80-89$ & 364 & 51 & 14 & \\
\hline$\geq 90$ & 33 & 11 & 25 & \\
\hline Nature of the surgery & & & & $p=0.0001,1 d f, \chi^{2}=85.96$ \\
\hline Elective & 1490 & 80 & 5 & \\
\hline Emergency & 277 & 61 & 22 & \\
\hline Surgical intent & & & & $p=0.0001,1 d f, \chi^{2}=41.66$ \\
\hline Curative & 1339 & 73 & 6 & \\
\hline Palliative & 377 & 59 & 16 & \\
\hline ASA grade & & & & $P=0.0001,1 d f, \chi^{2}=192.68$ \\
\hline ASA I & 497 & 8 & 2 & \\
\hline ASA \| & 570 & 28 & 5 & \\
\hline ASA III & 477 & 38 & 8 & \\
\hline ASA IV & 207 & 59 & 29 & \\
\hline ASA V & 4 & 5 & 80 & \\
\hline Local complications & & & & NS \\
\hline No & 1214 & 87 & 7 & \\
\hline Yes & 555 & 54 & & 10 \\
\hline Systemic complications & & & & $p=0.0001,1 d f, \chi^{2}=406.21$ \\
\hline No & 1443 & 26 & 2 & \\
\hline Yes & 326 & 115 & 35 & \\
\hline
\end{tabular}

of patients over the age of 80 years were not staged, specifically, $18 \%$ of cases in octogenarians and $45 \%$ in nonagenarians. These worrying figures are consistent with rates of $19 \%$ (5) and 23\% (2) reported for patients above 75 years of age, and those published by the Cancer Collaborative Group (6): $3.9 \%$ of patients younger than 65 years old, $6.1 \%$ of 65 - to 74 -year-olds, $9.0 \%$ of 75 - to 84 -year-olds and $17.3 \%$ of those 85 years of age or older. Another important fact is that screening programmes for colorectal cancer are carried out in populations aged between 50 and 69 years of age (22) while, as in our series, individuals older than 70 years old represent some $60 \%$ of cases. Indeed, some authors have suggested that the option of screening should be offered up to the age of 80 or even 85 (23).

Table VI. Mortality analysis by age group in operated patients

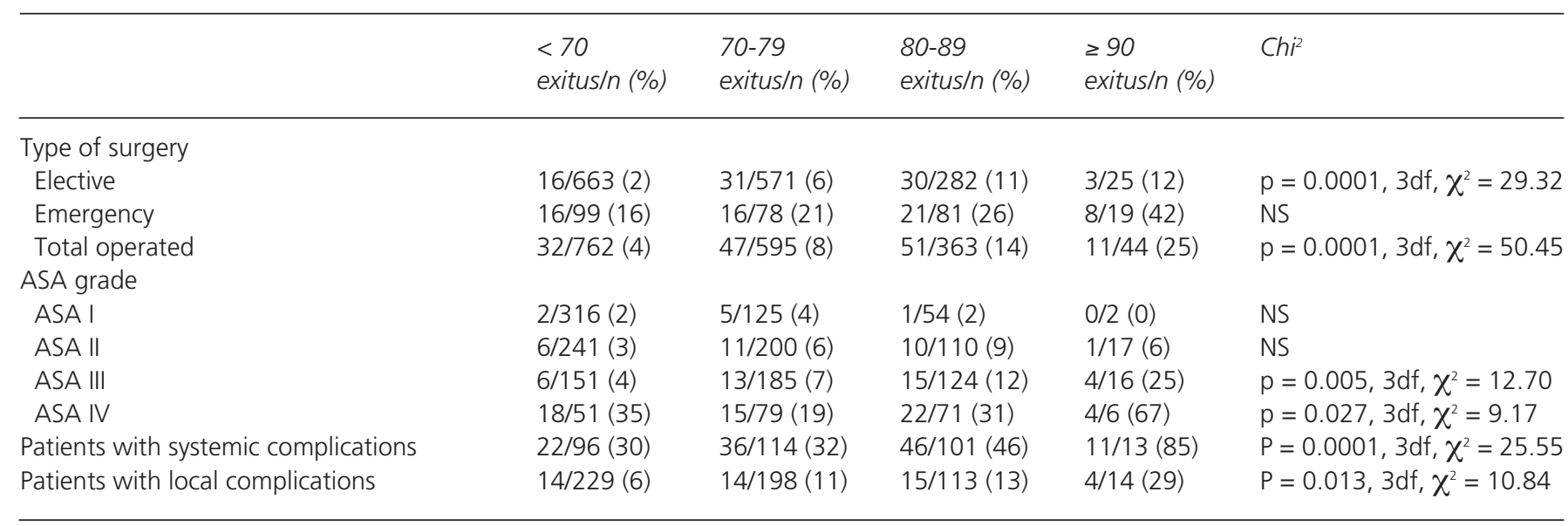


Table VII. Mortality analysis. Logistic regression

\begin{tabular}{|c|c|c|c|c|c|}
\hline & \multirow{2}{*}{$\begin{array}{l}\text { Df. } \\
\text { Higher }\end{array}$} & \multirow{2}{*}{$\begin{array}{l}\text { Sig. } \\
\text { Lower }\end{array}$} & \multirow{2}{*}{$\begin{array}{l}\text { Exp (B) } \\
\text { Higher }\end{array}$} & \multicolumn{2}{|c|}{ C.I. $95.0 \%$ for $\operatorname{Exp}(B)$} \\
\hline & & & & Lower & Higher \\
\hline Age & 1 & 0.016 & 1.865 & 1.123 & 3.095 \\
\hline Sex & 1 & 0.871 & 0.960 & 0.582 & 1.582 \\
\hline Nature of the surgery & 1 & 0.001 & 2.402 & 1.422 & 4.058 \\
\hline ASA grade & 1 & 0.000 & 3.216 & 1.945 & 5.318 \\
\hline Stage of the tumour & 1 & 0.152 & 2.227 & 0.746 & 6.654 \\
\hline Local complications & 1 & 0.902 & 0.969 & 0.589 & 1.594 \\
\hline Systemic complications & 1 & 0.000 & 30.474 & 17.374 & 53.453 \\
\hline Constant & 1 & 0.000 & 0.006 & & \\
\hline
\end{tabular}

There were significant differences between the four age groups studied in the percentages of patients who received surgical treatment, the rates being $96 \%, 85 \%$, and $59 \%$ in those under 80 (our first two groups combined), octogenarians, and nonagenarians, respectively. These figures are comparable though slightly lower than the figure of $87 \%$ of patients over 75 years of age undergoing surgery reported by Aparicio et al. (5). The differences are even more significant when the overall rates of resection are analysed, these rates being $90 \%, 84 \%, 68 \%$ and $43 \%$ for the $<70$, $70-79,80-89$ and $\geq 90$ age groups, respectively. A systematic review carried out by the Colorectal Cancer Collaborative Group (6) analysed surgical data on 34,194 patients, with individuals divided into four age groups: younger than $65,64-74,75-84$ and over 84 years of age. In that study, the rates of curative surgery observed were similar to those for the patients in our series who underwent surgery $(80 \%$ and $78 \%$ in the younger two age groups, $74 \%$ for those 80 -
89 years old and $66 \%$ for those $\geq 90$ years old). However, Aparicio et al. (5) reported rates of curative resection of only $48 \%$ in patients older than 75 years old, which contrast with the figure of $92 \%$ for the same age group published by Faivre-Finn et al. (14).

In our univariate analysis, postoperative mortality was associated with increasing age, the surgery being carried out as an emergency procedure and with palliative intent, advanced tumour stages and higher perioperative risk (ASA grade), which is in line with the findings of other authors $(2,3,5)$. However, in the multivariate analysis, the main factors associated with mortality were the emergency nature of the surgery, the ASA grade, and the presence of systemic complications, the weight of age being significantly lower than that indicated by the univariate analysis.

It should be highlighted that when we compared mortality between biologically strong and otherwise healthy patients (ASA I and ASA II) there were no significant dif-

Table VIII. Comparative analysis of morbidity by age group

\begin{tabular}{|c|c|c|c|c|c|}
\hline & $\begin{array}{l}<70 n=763 \\
\text { cases (\%) }\end{array}$ & $\begin{array}{l}70-79 n=596 \\
\text { cases (\%) }\end{array}$ & $\begin{array}{l}80-89 n=363 \\
\text { cases (\%) }\end{array}$ & $\begin{array}{l}\geq 90 n=44 \\
\text { cases (\%) }\end{array}$ & $\mathrm{Chi}^{2}$ \\
\hline Local complications & $229(30)$ & $198(33)$ & $113(31)$ & $14(32)$ & NS \\
\hline Wound infection & $109(14)$ & $87(15)$ & $43(12)$ & $5(11)$ & NS \\
\hline Anastomotic fistula & $63(8)$ & $48(8)$ & $23(6)$ & $6(14)$ & NS \\
\hline Abdominal Abscess & $28(4)$ & $23(4)$ & $10(3)$ & $0(0)$ & NS \\
\hline Systemic complications & $96(13)$ & $114(19)$ & $101(28)$ & $13(30)$ & $p=0.0001,3 d f, \chi^{2}=42.62$ \\
\hline Heart & $10(1)$ & $21(4)$ & $28(8)$ & $8(18)$ & $p=0.0001,3 d f, \chi^{2}=53.19$ \\
\hline Respiratory & $25(3)$ & $33(6)$ & $34(9)$ & $5(11)$ & $p=0.0001,3 d f, \chi^{2}=20.64$ \\
\hline Renal & $3(1)$ & $9(2)$ & $8(2)$ & $5(11)$ & $p=0.0001,3 d f, \chi^{2}=38.60$ \\
\hline Cerebrovascular & $2(1)$ & $3(1)$ & $4(1)$ & $1(2)$ & NS \\
\hline Thromboembolism & $3(1)$ & $9(2)$ & $7(2)$ & $0(0)$ & NS \\
\hline
\end{tabular}


ferences between the four age groups analysed. It is clear that the presence of associated disorders, such as heart disease, bronchopneumonia, and renal failure, makes older patients more fragile, which translates to a significant increase in mortality among this group. From all this, we can draw the conclusion that age by itself is not a factor on which to base decisions, especially in patients with no severe associated disorders. We also note that excision of tumour through the anus is an option for the treatment of early rectal cancer in elderly patients with relevant comorbidities (24).

Our study shows that the rate of postoperative complications progressively increases with age. This can be attributed to systemic complications, in particular of the cardiovascular, respiratory and renal systems, generally corresponding to a worsening of pre-existing comorbidities. Patients who develop these complications have a higher risk of postoperative death. However, there were no significant differences either in the overall rate of local complications (infection of the surgical wound, anastomotic fistulae or intra-abdominal abscesses) or when rates of such complications were analysed separately. These findings agree with those of other authors $(6,20,21,25-29)$.

On the other hand, it has been reported that the length of the postoperative stay increases in the most elderly patients $(5,21)$, but this was not corroborated our data, which indicate that this parameter is not affected by patient age.

To conclude, we can state that the rates of surgical treatment, tumour resection, and surgery with intention to cure dramatically decrease in octogenarian and nonagenarian patients, while the weight of age in operative mortality due to colon cancer in such patients is much lower than that of other variables such as the nature and intent of the surgery (emergency or elective; curative or palliative), the perioperative risk (ASA grade) and the occurrence of severe systemic complications. In particular, local morbidity is not influenced by age, whereas systemic morbidity does increase in octogenarian and nonagenarian patients, linked to underlying heart, respiratory and renal diseases.

Given that clinical trials are the main method for assessing the efficacy of the treatment of cancer patients, trials should be carried out specifically focusing on elderly patients to assess the risks and benefits of various approaches to treating colorectal cancer, including surgery and/or neoadjuvant or adjuvant therapies, in this apparently highly vulnerable population.

\section{DECISION MAKING IN OCTOGENARIAN AND NONAGENARIAN PATIENTS}

Given the great variability in functional deterioration between elderly individuals, one of the first factors to bear in mind is the need to establish the biological age of a patient. It is also important to estimate their life expectancy, which depends on associated disorders and functional status as well as their chronological age. In a high percentage of patients older than 80 years of age, life expectancy is far longer than the time to the development of metastasis that may compromise survival. The second step is then to assess whether the cancer represents a threat to the health or functioning of the individual with respect to their life expectancy. Lastly, the third consideration is whether the cancer or potential complications are a threat to the functional status and the quality of life of the patient. Accordingly, the risk of surgery must be weighed against the risk of not treating surgically. This decision-making process requires that the specialists involved (surgeons, gastroenterologists, and oncologists, among others) have sufficient understanding of the patient s life expectancy, the natural progress of the disease and the surgical risk in each patient.

\section{REFERENCES}

1. Área de Epidemiología Ambiental y Cáncer. Centro Nacional de Epidemiología. Instituto de Salud Carlos III. Ministerio de Consumo. Planificación sanitaria. La situación del cáncer en España. 2005

2. Damhuis RAM, Meurs CJC, Meijer WS. Postoperative mortality after cancer surgery in octogenarians and nonagenarians: results from a series of 5,390 patients. World Journal of Surgical Oncology 2005;3:71-3.

3. Golfinopoulos V, Pentheroudakis G, Pavlidis N. Treatment of colorectal cancer in the elderly: a review of the literature. Cancer Treat Rev 2006;32(1):1-8.

4. Talarico L, Chen G, Pazdur R. Enrollment of elderly patients in clinical trials for cancer drug registration: a 7-year experience by the US Food and Drug Administration. J Clin Oncol 2004;22(22):4626-31.

5. Aparicio T, Navazesh A, Boutron I, Bouarioua N, Chosidow D, Mion $\mathrm{M}$, et al. Half of elderly patients routinely treated for colorectal cancer receive a sub-standard treatment. Crit Rev Oncol Hematol 2009;71 (3):249-57.

6. Colorectal Cancer Collaborative Group. Surgery for colorectal cancer in elderly patients: a systematic review. Lancet 2000;356(9234):96874.

7. Arenal JJ, de Teresa G, Tinoco C, Toledano M, Said A. Abdominal surgery in nonagenarians: short-term results. Surg Today 2007;37 (12):1064-7.

8. Rigberg D, Cole M, Hiyama D, McFadden D. Surgery in the nineties. Am Surgeon 2000;66(9):813-6.

9. Warner MA, Hosking MP, Lobdell CM, Offord KP, Melton LJ 3rd". Surgical procedures among those $>90$ years of age. A population-based study in Olmsted county, Minesota, 1975-1985 Ann Surg 1988;270 (4):380-6.

10. Hosking MP, Warner MA, Lobdell CM, Offord KP, Melton LJ3rd Outcomes of surgery in patients 90 years of age and older. JAMA 1989;216(13):1909-15.

11. Cohen JR, Johnson H, Eaton S, Sterman H, Wise L. Surgical procedures in patients during the tenth decade of life. Surgery 1988;104(4):64651.

12. Daniels IR, Wilkins RA, Simson JNL. Audit of the outcome of emergency surgery in nonagenarians. Br J Surg 2000;87(Supl. 1):76.

13. Ackermann RJ, Vogel DL, Jhonson LA, Ashley DW, Solis MM. Surgery in nonagenarians: morbidity, mortality and functional outcome. J Fam Pract 1995;40(2):129-35.

14. Faivre-Finn C, Bouvier-Benhamiche AM, Phelip JM, Manfredi S, Dancourt V, Faivre J. Colon cancer in France: evidence for improvement in management and survival. Gut 2002;51(1):60-4.

15. Arai T, Takubo K, Sawabe M, Esaki Y. Pathologic characteristics of colorectal cancer in the elderly: a retrospective study of 947 surgical cases. J Clin Gastroenterol. 2000;31(1):67-72.

16. Waldron RP, Donovan IA, Drumm J, Mottram SN, Tedman S. Emergency presentation and mortality from colorectal cancer in the elderly. Br J Surg 1986;73(3):214. 
17. Cogbill CL. Operation in the aged. Arch Surg 1967;94(2):202.

18. Isbister WH. Colorectal surgery in the elderly: an audit of surgery in octogenarians. Aust N Z J Surg 1997;67(8):557-61.

19. Aapro MS, Köhne CH, Cohen HJ, Extermann M. Never too old? Age should not be a barrier to enrollment in cancer clinical trials. Oncologist 2005;10(3):198-204.

20. Arenal JJ, Benito C, Concejo MP, Ortega E. Colorectal resection and primary anastomosis in patients aged 70 and older: prospective study. Eur J Surg 1999;165(6):593-7.

21. Kingston RD, Jeacock J, Walsh S, Keeling F. The outcome of surgery for colorectal cancer in the elderly: a 12-year review from the Trafford Database. Eur J Surg Oncol 1995;21(5):514-6.

22. Navarro M, Binefa G, Blanco I, Guardiola J, Rodríguez-Moranta F, Peris M; Catalan Colorectal Cancer Screening Pilot Programme Group. Colorectal cancer screening: strategies to select populations with moderate risk for disease. Rev Esp Enferm Dig 2009;101(12):855-60.

23. Bixquert-Jiménez M. Selective colorectal cancer screening in average-risk populations. Rev Esp Enferm Dig 2009;101(12):821-9.

24. Palma P, Horisberger K, Joos A, Rothenhoefer S, Willeke F, Post S. Local excision of early rectal cancer: is transanal endoscopic micro- surgery an alternative to radical surgery? Rev Esp Enferm Dig 2009; 101(3):172-8.

25. Shahir MA, Lemmens VE, van de Poll-Franse LV, Voogd AC, Martijn $\mathrm{H}$, Janssen-Heijnen ML. Elderly patients with rectal cancer have a higher risk of treatment-related complications and a poorer prognosis than younger patients: a population-based study. Eur J Cancer 2006;42 (17):3015-21.

26. Puig-La Calle J Jr, Quayle J, Thaler HT, Shi W, Paty PB, Quan SH, et al. Favorable short-term and long-term outcome after elective radical rectal cancer resection in patients 75 years of age or older. Dis Colon Rectum 2000;43(12):1704-9.

27. Chiappa A, Zbar AP, Bertani E, Biella F, Audisio RA, Staudacher C. Surgical outcomes for colorectal cancer patients including the elderly. Hepatogastroenterology 2001;48(38):440-4.

28. Quaglia A, Tavilla A, Shack L, Brenner H, Janssen-Heijnen M, Allemani $\mathrm{C}$, et al.; EUROCARE Working Group. The cancer survival gap between elderly and middle-aged patients in Europe is widening. Eur J Cancer. 2009; 45(6):1006-16.

29. Endreseth BH, Romundstad P, Myrvold HE, Bjerkeset T, Wibe A; Norwegian Rectal Cancer Group. Rectal cancer treatment of the elderly. Colorectal Dis 2006;8(6):471-9. 